\title{
Planejamento urbano e participação social em pequenas cidades
}

\author{
Urban planning and social participation in small cities
}

\author{
lara Soares de França \\ Valéria Aparecida Moreira Costa \\ Marcela Alves Fonseca
}

Universidade Estadual de Montes Claros - UNIMONTES - Montes Claros - Minas Gerais - Brasil

\begin{abstract}
Resumo: Este estudo analisa a visão da população, em municípios com contingente populacional inferior a 100 mil habitantes do Norte de Minas Gerais, sobre o planejamento urbano e a participação social. $O$ artigo se divide em três partes articuladas. Na primeira, apresenta-se elementos de reflexão teórico conceitual sobre os temas cidades, urbanização, problemas urbanos e planejamento urbano no Brasil. A segunda aborda estudos sobre pequenas cidades e, ainda, evidenciase aspectos da urbanização na área de análise, isto é, no Norte de Minas Gerais. $\mathrm{Na}$ última parte analisa-se a visão da população sobre o planejamento urbano nas cidades pesquisadas. A pesquisa de campo foi realizada em onze municípios e consistiu na aplicação de questionário semiestruturado à população, coleta de dados demográficos, elaboração de mapa, gráficos e tabela.
\end{abstract}

Palavras-chave: Problemas Urbanos. Planejamento. Pequenas Cidades.

\begin{abstract}
This study analyzes the vision of the population, in municipalities with a population of less than 100 thousand inhabitants of the North of Minas Gerais, on urban planning and social participation. The article is divided into three articulated parts. In the first one, elements of theoretical conceptual reflection on the themes cities, urbanization, urban problems and urban planning in Brazil are presented. The second one deals with studies on small cities and also shows aspects of urbanization in the area of analysis, that is, in the North of Minas Gerais. In the last part we analyze the population's view of urban planning in the cities surveyed. Field research was carried out in eleven municipalities and consisted in the application of a semi-structured questionnaire to the population, collecting demographic data, mapping, charts and tables.
\end{abstract}

Keywords: Urban Problems. Planning. Small cities. Program. 


\section{Introdução}

A ocupação do espaço geográfico, ambiente natural e cultural, seja rural ou urbano, é expressão material visível das relações econômicas, da intervenção humana em detrimento da natureza e, da configuração do território. Na sua essência, a cidade é ao mesmo tempo produto, meio e condição de reprodução da sociedade.

As possibilidades de mudanças da realidade econômica, socioespacial e ambiental das cidades devem ser analisadas. A construção de cidades com melhores níveis de vida para a sua população requer ação política e sensibilização humana daqueles interessados na realidade social urbana (moradores, planejadores, administradores, universidades, ONGs, movimentos sociais, dentre outros).

As políticas públicas através da ação do Estado são cruciais nesse cenário não somente para viabilizar a produção econômica, mas, também para garantir os direitos urbanos (saúde, educação, emprego, lazer, moradia, entre outros). Deve-se diminuir as desigualdades sociais e regionais, com prioridade para os investimentos públicos nas periferias das cidades e em locais de baixa renda diversos onde os problemas urbanos são mais graves.

No Brasil há 3.080 municípios com população total inferior a $20 \mathrm{mil}$ habitantes. Neles vivem 32.108.798 pessoas, conforme estimativa do IBGE para 2018. Somando os municípios entre 20 mil e 50 mil habitantes que corresponde a 1096, tem-se uma população total superior a 65 milhões de pessoas. Representam 75\% do total de municípios e 31,4\% da população brasileira. Em Minas Gerais são 669 municípios com menos de 20 mil habitantes, totalizando 5.224 .980 pessoas residentes. Entre 20 mil e 50 mil habitantes são 113 municípios com população total de 3.406.653 residentes. Somando os dois estratos têm-se 92\% dos municípios mineiros com $41 \%$ da população residente. (CENSO DEMOGRÁFICO, IBGE, 2010).

Esse contingente expressivo e a importância que assumem na rede urbana brasileira demonstram ser fundamental pensar o processo de planejamento e urbanização dos pequenos municípios, com vistas à melhoria da qualidade de vida da população que ali reside.

A pouca ou a ausência de participação da população local no planejamento urbano, bem como a falta de instrumentos, como o Plano Diretor, em cidades com menos de 20 mil habitantes é um desafios à produção de cidades com uma justa distribuição dos benefícios da urbanidade.

Nessa perspectiva, este artigo analisa a visão da população, em municípios com contingente populacional inferior a 100 mil habitantes do Norte de Minas Gerais, sobre o planejamento urbano e a participação social. A pesquisa foi realizada em onze municípios com população inferior a 100 mil habitantes, localizados na mesorregião Norte de Minas Gerais.

Os procedimentos metodológicos utilizados para desenvolvimento do artigo consistiram em: a) revisão bibliográfica sobre cidades, urbanização, planejamento urbano e pequenas cidades; b) levantamento de dados por meio da pesquisa de campo realizada entre os anos de 2017 e 2018, com visita aos municípios de Bocaiúva, Capitão Enéas, Francisco Dumont, Glaucilândia, Grão Mogol, Itacambira, Janaúba, Januária, Japonvar, Mirabela e Pirapora, localizados no Norte de Minas. Para a coleta de informações foram aplicados questionários semiestruturados, com dez questões cada, com opções de respostas fechadas e também abertas, para um público entre 30 e 50 moradores dos municípios. A organização dos resultados se deu pela sistematização em mapa, gráficos e tabela no programa Microsoft Office Excel. As dez questões presentes no roteiro das entrevistas foram agrupadas em blocos, um bloco que se referem aos problemas dos municípios e seus responsáveis, outro sobre participação no planejamento urbano e, outro sobre o conhecimento do Plano Diretor e participação. Foram utilizadas técnicas de geoprocessamento com 0 software Arc Giz para elaboração do mapa de localização. Soma-se a isso, pesquisa de dados demográficos e do Perfil dos Municípios Brasileiros no IBGE (2015). 


\section{Cidades, Urbanização e Desafios do Planejamento Urbano no Brasil}

O fenômeno de urbanização caracteriza-se pela concentração densa de população em aglomerações de caráter urbano. Constitui um processo complexo que envolve vertentes humanas, sociais e territoriais, traduzindo-se numa alteração do modo de vida, com a incorporação de novos valores, novos comportamentos, em que são revelados novos tipos e formas de consumo, e, também novas formas de habitar. (CASTELLS, 1972). Diante disso, a urbanização pode ser considerada "um processo social e espacial que se refere às mudanças comportamentais e sociais que ocorrem na sociedade, como resultado de pessoas morando nas cidades". (CLARK, 1991, p.61).

Como forma espacial e material engendrada ao processo de urbanização, constituem-se as cidades em suas condições históricas, econômicas, sociais e culturais. A respeito do par dialético "cidade e urbanização", Spósito (1999, p.86) adverte para

[...] o fato de que a urbanização é um processo e a cidade, uma forma espacial não deve nos levar à concepção estatística da realidade urbana, a partir da qual a leitura da cidade deve ser feita através de sua morfologia, e a da urbanização através de seu processo. É apenas na relação entre o processo e a forma engendrada que podemos compreender como um dado arranjo sócio-espacial é, ao mesmo tempo produto e produtor da realidade.

Beaujeu-Garnier (1980, p. 21-22) entende que, entre as diferentes tentativas de elaboração do conceito de cidade o importante é considerar

[...] a cidade, concentração de homens, de necessidades, de possibilidades de toda a espécie (trabalho, informação), com uma capacidade de organização e transmissão, é ao mesmo tempo sujeito e objeto. Enquanto objeto, a cidade existe materialmente; atrai e acolhe habitantes aos quais fornece, através da sua produção própria, do seu comércio e dos seus diversos equipamentos, a maior parte de tudo o que eles necessitam; a cidade é o lugar que favorece os contatos de toda natureza e maximiza os resultados; a cidade contribui essencialmente para a dupla ligação entre o espaço periférico que mais ou menos domina e o espaço longínquo com o qual mantém ligações complexas.

Inseridas no modo de produção capitalista, considerando as desigualdades por ele causadas, as cidades estão carregadas de problemas urbanos. Em suma, a cidade precisa ser analisada, tanto como forma espacial quanto como organização social.

Depreende-se, portanto, que a criação da cidade resulta da interação do homem com o meio, da dialética homem/natureza, um produto histórico cultural resultante da construção humana. A compreensão de seu significado envolve uma gama de aspectos de ordem espacial; temporal; social, política e econômica, pois

A cidade é uma realização humana, uma criação que vai constituindo ao longo do processo histórico e que ganha materialização concreta, diferenciada, em função de determinações históricas específicas. [...] Ela seria assim, em cada época o produto da divisão do tipo e dos objetos de trabalho, bem como do poder nela centralizado. Por outro lado, é necessário pensar que a cidade só pode ser pensada na sua articulação com a sociedade global, levando-se em conta a organização política, e a estrutura do poder da sociedade, a natureza e repartição das atividades econômicas, as classes sociais (CARLOS, 2015, p.57).

O Brasil é um país eminentemente urbano onde $84 \%$ da população do país vive em cidades (IBGE, 2010). Santos (1982) constata que, para se compreender as razões do crescimento urbano tanto do ponto de vista geral quanto de um caso específico, "torna-se necessário apreender a natureza dos fenômenos mundiais ligados ao processo de urbanização e ao mesmo tempo interpretar os seus fatores locais, regionais e nacionais".

Os principais problemas do crescimento urbano [...] são problemas relativos à moradia, aos serviços públicos, ao emprego e ao desenvolvimento nacional. Também os problemas da paisagem estão aí relacionados na problemática urbana. (SANTOS, 1982, p.20).

Corrêa (2005, p.29) explica os problemas urbanos vivenciados pela população e os processos 
de segregação espacial e exclusão social a eles correlacionados

$\mathrm{Na}$ sociedade de classes verificam-se diferenças sociais no que se refere ao acesso aos bens e serviços produzidos socialmente. No capitalismo as diferenças são muito 'grandes, e maiores ainda em países como, entre outros, os da América Latina. A habitação é um desses bens cujo acesso é seletivo: parcela enorme da população não tem acesso, quer dizer, não possui renda para pagar o aluguel de uma habitação decente e, muito menos, comprar um imóvel. Este é um dos mais significativos sintomas de exclusão que, no entanto, não ocorre isoladamente: correlatos a ela estão a subnutrição, as doenças, o baixo nível de escolaridade, o desemprego ou o subemprego e mesmo o emprego mal-remunerado.

Com a elevada urbanização intensificada no final do século $X X$, as grandes e médias cidades do Brasil, notadamente, começaram a apresentar graves problemas urbanos, como a degradação ambiental, favelização, desemprego, falta de habitação, violência, entre outros. Ausência ou ineficácia de serviços públicos como escolas, creches, postos de saúde e áreas de lazer, agravam ainda mais o quadro urbano. Estes são alguns exemplos de problemas ambientais, infraestruturais e sócio-econômicos que emergem do acelerado crescimento populacional urbano num contexto de ineficiência de planejamento e gestão urbana.

Além da problemática urbana que caracteriza a urbanização e as cidades no Brasil da atualidade, verifica-se uma série de transformações econômicas, socioespaciais e culturais na sociedade brasileira com novas bases, escalas, condições e processos. Nesse cenário, novas dinâmicas e características espaciais são produzidas no desenvolvimento do modo capitalista de produção.

Nessa perspectiva, Ribeiro (2006) ler a dinâmica da urbanização brasileira face a uma nova divisão territorial do trabalho, tendo em vista as diversas escalas da produção e os impactos da reestruturação da economia com transformações não somente no urbano e na cidade, mas também na sociedade brasileira.
É a partir dessa consideração que se interpreta que a urbanização brasileira e a produção das cidades no contexto contemporâneo se complexifica e atinge as diversas escalas urbanas, para além da polarização metropolitana.

Conforme afirmou Corrêa (2001), foi somente na segunda metade do século $X X$, mediante a intensificação dos processos iniciados na fase anterior e do desenvolvimento de novos aspectos ligados, sobretudo, a mundialização da economia e inserção do Brasil nesse contexto, que, efetivamente, a industrialização se consolidou e a urbanização atingiu dimensões jamais vistas, bem como, a rede urbana brasileira se tornou mais complexa e sofreu mudanças mais intensas.

Das dinâmicas atuais que engendram a urbanização brasileira, tem-se o crescimento das pequenas cidades e os papéis que desempenham na Rede Urbana Brasileira. As pequenas cidades tornaram-se um tema desenvolvido no meio acadêmico considerando sua dinâmica econômica e a realidade socioespacial e cultural em que se inserem, e, ainda a sua importância para entender o significado do processo de urbanização brasileiro atual. Para Santos (1979) é importante preservar o papel das cidades locais, sem, consagrar e conservar disparidades, integrando-as num mecanismo de crescimento que seja geral e não seletivo.

Os desafios urbanos atuais são frutos de modelos econômicos, políticos e socio-espaciais, que geraram, via de regra, no caso brasileiro, um cenário de crise urbana com problemas de ausência ou ineficiência de planejamento. Os agentes urbanos (os Proprietários dos meios de produção, Proprietários Fundiários, Promotores Imobiliários, Grupos Sociais e o Estado), na visão de Corrêa (2005), apropriam e produzem a cidade em diferentes usos, funções e tempos, possuem interesses ora específicos, ora comuns e, ainda, contraditórios, daí a complexidade de suas práticas.

As ciências urbanas devem avançar na análise das estratégicas e práticas, sua natureza, a escala de ação dos agentes urbanos e o seus efeitos na cidade. Estado e Sociedade realizam importantes 
ações nesse contexto. Conforme projetado por Lefebvre (1999) a problemática urbana no quadro contemporâneo é moldada pela produção social do espaço urbanizado. Essa problemática é planejada e orquestrada com o crescente poder do Estado, agente de regulação e de reestruturação espacial.

O Estado desempenha um papel importante na estruturação urbana quer seja como agente político, econômico ou social. Sobre o papel do Estado na sociedade capitalista no contexto de ações de planejamento urbano, Rolnik (2005) explica que o mesmo acredita que quando se planeja uma cidade, pode-se eliminar seus defeitos, tornando-a ideal. A ideia dessa cidade mecanizada é vista claramente nas utopias, no imaginário de diversos autores, que apesar de não se tornarem realidade, expressa claramente um plano de intervenção do Estado na cidade, via planejamento, que se reflete até os dias de hoje.

Nesse âmbito, Duarte (2007, p.22) trata da noção de planejamento e seus objetivos

Podemos definir planejamento como o conjunto de medidas tomadas para que sejam atingidos os objetivos desejados, tendo em vista os recursos disponíveis e os fatores externos que podem influir nesse processo. Nesse sentido, podemos dizer que o planejamento reconhece, localiza as tendências ou as propensões naturais (locais e regionais) para o desenvolvimento [...] (DUARTE, 2007, p. 22).

Uma outra definição de planejamento é indicada por Caldas (2015, p.52) e abarca as suas dimensões e importância. Nas palavras do autor, o planejamento refere-se ao "um conjunto de competências capazes de orientar o desenvolvimento urbano, visando alcançar maior equilíbrio social, cultural, ambiental e econômico, assim como equidade, pelo conjunto da sociedade, nas formas de apropriação do espaço socialmente construído".

Monte-Mór (2008) analisa os novos arranjos

do Estado brasileiro, base importante para 0 planejamento urbano.

Em suas várias instancias, a fragilização relativa do Estado como 0 agente hegemônico promotor e regulador da economia te tido como contrapartida o fortalecimento das articulações na sociedade civil, internas aos espaços e setores das economias nacionais e com espaços econômicos distantes. Por outro lado, o desmonte do Estado de Bem_Estar junto com o modelo fordista mundial, particularmente no Brasil, tem resultado também no fortalecimento das funções municipais. Ou seja, no contexto "neoliberal" prevalecente, o município temse tornado o refúgio, talvez o último reduto do que restou do Estado de Bem-Estar. Esse papel foi fortalecido pela Constituição de 1988, que expandiu e descentralizou atribuições e atividades para o município, ainda que nem sempre acompanhadas dos recursos necessários. (MONTE-MÓR, 2008, p.130).

Maricato (2002) considera o planejamento urbano um caminho necessário no contexto urbano nacional.

\begin{abstract}
Um processo de urbanização excludente, predatório e marcado por desperdício de recursos. Quais são os cenários das nossas cidades na próxima década? Existe outra opção que não seja a ação planejada, tanto para a recuperação da cidade degradada quanto para alguma orientação de crescimento futuro? (MARICATO, 2002, p.173-174).
\end{abstract}

Nessa perspectiva, o Estado é o agente central do processo de planejamento urbano. Estado, assim entendido como poder público, estratificado em poder central (União), unidades federativas e municípios. Cabe aos municípios, os pequenos também, o papel protagonista no planejamento urbano.

A década de 1980 marca um cenário importante para a política urbana no Brasil, no marco regulatório, com fortes implicações espaciais. A Constituição Federal Brasileira de 1988 no Capítulo II da Política Urbana, artigos 182 e 183, viabilizou novos instrumentos urbanísticos, democratizou o solo urbano e projetou maior autonomia aos municípios a partir de instrumentos de planejamento e gestão urbana.

O Estatuto da Cidade, Lei Federal 10.257 de 10 de Julho de 2001 também representa um avanço nessa direção. De caráter progressista, essa Lei reuniu as normas concernentes à ação do poder público na regulação do uso da propriedade urbana em favor do interesse e bem-estar coletivos. 
Nesse contexto, o Movimento Nacional de Reforma Urbana/MNRU lutava pela democratização do espaço da cidade incorporando novos atores, novos temas, mudanças nas políticas locais e, sobretudo, a participação social. (CYMBALISTA, 2006). O autor aponta que a CFB e o Estatuto da Cidade redefiniram a função do Plano Diretor Municipal como uma das fronteiras mais dinâmicas da Reforma Urbana no Século XXI, já que "[...] ressignificaram o instrumento, transformando-o na peça básica da política urbana do município, responsável pela definição de elementos estratégicos na esfera local como o cumprimento da função social da propriedade". (CYMBALISTA, 2006, p.36).

A participação da população local nos processos de planejamento e gestão urbana é bastante complexa. A esse respeito Souza (2008) avalia que continua "[...] sendo negligenciada ou se resume a uma falsa participação, sendo que a "ditadura" agora não é mais a do Estado "disciplinando" o capital na organização do espaço urbano, mas sim, a do capital sobre o Estado e sobre a cidade. (SOUZA, 2008, p.138-139). Mas, Castells (2000) pontua que os atores sociais com base em materiais culturais constroem uma nova identidade que redefine sua posição na sociedade, buscando a transformação de toda a estrutura social.

Independente do caminho a ser trilhada na busca de cidades mais justas é necessário qualificar e ampliar a participação popular nos processos de planejamento e gestão urbana de forma contínua e participativa, onde os problemas urbanos sejam pensados, debatidos, com vistas a busca de soluções e alternativas. Contribuindo assim para uma transformação aproximando-se da Prática Urbana, isto é, a Práxis Sócio espacial no pensamento de Lefebvre (1999), numa possível emancipação social, política e cultural. Aspectos da Urbanização e Planejamento nas
Pequenas Cidades no Norte de Minas Gerais

\section{Pequenas Cidades no Brasil: notas introdutórias}

Como ponto de partida para análise realiza-se a explanação de alguns conceitos sobre pequenas cidades e procedimentos de pesquisa, considerando a diversidade e singularidade desse tema no Brasil Urbano Moderno.

O estudo das pequenas cidades é relevante não somente no Brasil, mas também no mundo. Esses núcleos urbanos representam expressiva quantidade de centros e possuem uma área espacial importante no Brasil, despontaram demográfica e economicamente no final do século $X X$, num contexto da produção da desigualdade espacial do fenômeno urbano. (SPOSITO; SILVA, 2013).

Os autores do campo da Geografia Urbana, notadamente, especialistas no assunto no Brasil, consideram, além do critério estatístico, outros elementos para a análise das pequenas cidades, tais como: os papéis urbanos que desempenham na região em que se insere, a morfologia, a densidade, as atividades econômicas, os fluxos, os modos de vida e a cultura, entre outros.

O tamanho demográfico é um dos critérios mais utilizados nessa tarefa. Embora, o Instituto Brasileiro de Geografia e Estatística (IBGE) considera como pequena cidade todo aglomerado que apresenta uma população urbana inferior a 20.000 habitantes, para efeito desta pesquisa analisou-se onze municípios com população inferior a 100.000 habitantes localizados no Norte de Minas Gerais. Esta metodologia é importante como um parâmetro de pesquisa, isto é, um ponto de partida considerando o conjunto urbano, mas é fundamental avançar para outras perspectivas analíticas. O indicador estatístico não pode ser a única base para definir esses núcleos urbanos, se não levaria a simplificações de sua realidade.

Santos (1982) trata as pequenas cidades como cidades locais em diversos níveis, o que revela a sua diversidade no Brasil. Possuem uma dimensão populacional mínima com a função de servir as necessidades inadiáveis da população num processo 
de especialização do espaço. Há cidades locais que se inserem no contexto atual dos avanços tecnológicos e das transformações que as impactam. Ainda, conforme o autor, as cidades locais se diferenciam da cidade do campo onde o urbano está diretamente subordinado ao rural, apresentando poucas inovações e reduzida capacidade de atender a população com a oferta de produtos e serviços. Estas pequenas cidades não possuem uma dinâmica econômica e centralidade expressivas, não podendo com isso, atender sua população com a oferta de bens e serviços diversos.

O rural é um forte elemento analítico para os estudos de pequenas cidades. Ele pode ser entendido como uma representação social que está presente na pequena cidade através dos hábitos, costumes, valores e tradições dos moradores. Nesses espaços há intensa interação entre os valores rurais e urbanos na vida dos moradores. (SOARES, MELO, 2010, p. 244).

Wanderley (2001) reflete a pequena cidade a partir de seu caráter rural na urbanização e dinâmicas sociais. Para a autora isso se materializa desde o seu "povoamento reduzido e à predominância das paisagens 'naturais' e das relações de interconhecimento" (WANDERLEY, 2001, p.15). Corrêa (1999) define que a pequena cidade é um núcleo dotado da função de sede municipal no qual certa parte da população está engajada em atividades ligadas à transformação e circulação de mercadorias e prestações de serviços.

Sobre as relações estabelecidas entre as pequenas cidades no âmbito de uma rede urbana Spósito (2006, p.219-220) enfatiza:

As pequenas cidades têm sua dinâmica comandada por uma estrutura urbanoindustrial, o que significa dizer que "o comando vem do urbano", ainda que não apresentem uma multiplicidadade de papéis identificada com aquilo que atualmente é considerado como urbano.

Também nessa perspectiva, Endlich (2006) acrescenta que a dimensão analítica para as pesquisas sobre pequenas cidades não pode isolá-la do da rede urbana em que se insere. A autora defende que deve-se compreender as dinâmicas destas localidades em interação, em movimento, consoante a apreensão de uma realidade que considere os demais centros urbanos e fluxos humanos existentes entre eles.

Verifica-se então a diversidade e singularidade das pequenas cidades, como comentam Alves, Melo e Soares (2007, p. 08):

As pequenas cidades são bastante diferenciadas entre si. Esse fator ocorre tanto pela própria diversidade da formação espacial do país, bem como pelos processos locais de cada espacialidade, pela atuação dos agentes sociais e do estado e pelas particularidades sócioculturais, assim como pela sua localização geográfica, suas condições de acessibilidade, bem como pela maior ou menor inserção dos lugares na economia globalizada, entre outros.

Essas perspectivas teóricas e metodológicas apresentadas expressam os contextos sociais, econômicos, políticos e culturais específicos das pequenas cidades e as múltiplas dimensões de análise, para além da demográfica. Derivam de uma produção de pesquisadores que apontam para a análise do fenômeno urbano pela noção de Totalidade dos processos trabalhada por Lefebvre (1978).

Assim, pensar as cidades pequenas implica considerar as complexas relações com o mundo rural, as especificidades locais e regionais que singularizam o processo histórico de sua formação, além de não negligenciar as redes urbanas nas quais estão inseridas.

\section{O Norte de Minas Gerais}

De acordo com Oliveira et al (2000) o processo de ocupação e de formação regional e econômica do Norte de Minas Gerais se efetivou na segunda metade do século XVII com as correntes de povoamento vindas do norte, fruto da expansão dos currais de gado ao longo do Rio São Francisco e, pelo sul, das bandeiras paulistas. O século XVIII e inicio do século XIX caracteriza-se pela decadência da mineração na região central de Minas Gerais. Com isso, mudanças marcam o século XIX em relação aos fluxos de comércios. As principais atividades 
econômicas da região eram a pecuária bovina, e a cana-de-açúcar (cana, aguardente e rapadura). A produção de algodão também era importante na produção de tecidos e resultou, posteriormente, na implantação de indústria têxtil no final do século XIX. Culturas de subsistência estavam presentes na região Norte de Minas nesse período e representavam parcelas significativas da economia e do esforço humano.

Um importante fator que marca o processo de ocupação no Norte de Minas Gerais é a instalação de ferrovias, no inicio do século XX, em Montes Claros e Pirapora. Tal fato viabilizou a comercialização dos produtos e um maior intercâmbio entre os municípios da região. Pode-se dizer que foi nesse contexto que Montes Claros começou a alcançar a posição de centro econômico e político regional. (FRANÇA, 2012).

Outro marcante acontecimento na região deuse na segunda metade do século XX, década de 1960, quando o Estado e a União projetaram a região nortemineira à área de atuação da Superintendência de Desenvolvimento do Nordeste - SUDENE, por meio de auxílio a incentivos fiscais e financeiros. Nesse contexto, a indústria instala-se na região tendo como sede Montes Claros, que reunia as principais condições para abrigar tal atividade. (FRANÇA, 2012)

$A$ atividade industrial motivou a migração campo-cidade no Norte de Minas. A migração dos camponeses para as áreas urbanas gerou uma grande explosão demográfica em algumas cidades, por exemplo, Montes Claros $^{1}$. Diante disso, a indústria acelera o setor de serviços, dinamizando-o, e a urbanização é ativada. (FRANÇA, 2012).

Em relação à urbanização, Pereira (2004) pontua que o norte-mineiro é uma região que vem passando por um significativo processo de urbanização, o que contribuído para a formação de novas espacialidades: "[...] a mesorregião Norte de Minas se individualiza no contexto mineiro por apresentar uma formação socioespacial singular". (PEREIRA, 2004, p.12). A autora explica que a urbanização na região, em termos gerais, decorre da

1 No Censo 2010 (IBGE), sua população totalizou 361.915 habitantes; deste total, 95\% da população é combinação das forças de expulsão do campo com o crescimento das forças de atração das cidades. A região, tem no conjunto, mais da metade de sua população vivendo nas cidades. Mas, o processo de urbanização não ocorreu de forma homogênea. Houve, na última década, um aumento da população urbana em todos os municípios da região. Entretanto, a taxa de crescimento populacional urbano foi diferenciada entre os municípios e apenas em alguns a população urbana superou a rural. (PEREIRA, 2004, p.20-21).

A população total da mesorregião Norte de Minas, constatada pelo Censo Demográfico de 2010, foi de 1.610 .413 habitantes, sendo $69 \%$ população urbana e 31\% rural. Abrangendo uma área territorial de 128.602 km2, o Norte de Minas é uma região composta por oitenta e nove municípios. Compreende Sete Microrregiões: Bocaiuva, Grão Mogol, Janaúba, Januária, Montes Claros, Pirapora e Salinas. Dentre essas, Montes Claros se destaca como o mais importante e dinâmico centro urbano na região. (IBGE, 2010).

Montes Claros/MG é classificada como cidade média com grande importância regional no Norte de Minas, conforme demonstraram os estudos de Amorim Filho, Bueno e Abreu (1982); Andrade; Lodder (1979); França (2012, 2007); Pereira, Lemos (2004) e Pereira (2007).

Montes Claros se insere como cidade média não apenas pelo indicador populacional, mas, também, pelo dinamismo econômico, a prestação de serviços nas áreas da educação e saúde que a constitui como uma força de atração regional, a infraestrutura dos transportes, as centralidades urbanas por meio dos shopping-centers, vias especializadas e subcentros em comércios e serviços, além da atual expansão urbana vertical e horizontal por condomínios de alto luxo, edifícios, residenciais, aglomerados subnormais e os conjuntos habitacionais. (FRANÇA, 2007; LEITE, 2006; PEREIRA, 2007).

urbana. 
Mapa 1: Municípios da Região Norte de Minas selecionados para a Pesquisa

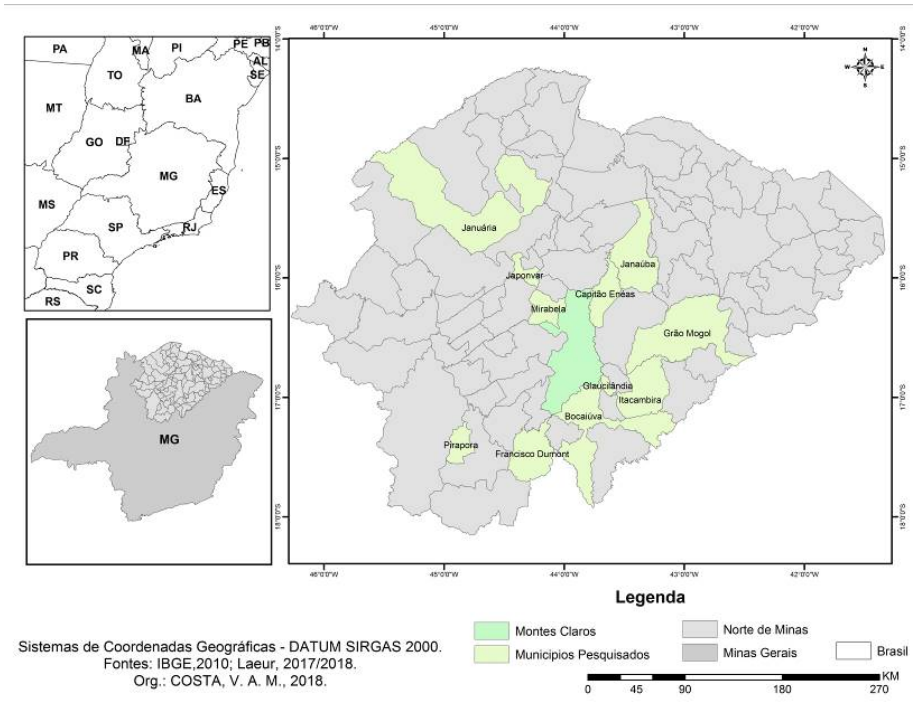

As pequenas cidades aqui estudadas (exceto Janaúba, Januária, Pirapora, e Bocaiuva), isto é, Mirabela, Japonvar, Capitão Enéas, Grão Mogol, Glaucilândia, Francisco Dumont e Itacambira não exercem influência sobre outras, sua dinâmica econômica restringe-se ao âmbito local. Sua urbanização caracteriza-se pelo aumento da população urbana, mas suas relações econômicas se realizam predominantemente no espaço rural, que por sua vez, não se industrializou, nem se modernizou.

Problemas urbanos, soluções e responsáveis: a visão da população local

A população entrevistada foi indagada sobre:

a) os principais problemas urbanos do município; b) soluções; c) principais responsáveis; d) conhecimento do Plano Diretor e, e) Participação na sua elaboração.

O gráfico 1 demonstra os principais problemas apontados pela população entrevistada. Para 55\% dos entrevistados a Saúde e a Infraestrutura são destaque, seguidos do Desemprego (14\%) e da Educação (10\%).
Gráfico 1 - PRINCIPAIS PROBLEMAS APONTADOS

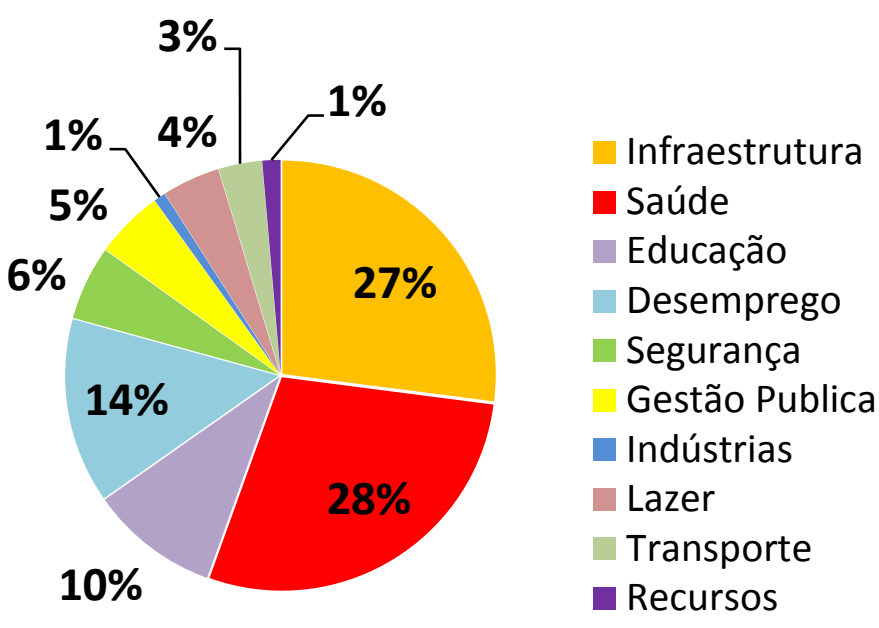

Fonte: Pesquisa Direta, 2018.

Notadamente, o acesso à saúde pública nos pequenos municípios, em geral, depende da rede básica e de média complexidade instalada no local e da associação/consorciamento com municípios polos para os atendimentos de alta complexidade e serviços de medicina diagnóstica.

No caso do Norte de Minas, o município de Montes Claros dispõe de uma ampla rede de serviços de saúde de alta complexidade. Já a infraestrutura envolve, desde pavimentação de vias públicas, saneamento básico, construção de praças e áreas verdes, de equipamentos públicos, dentre outros. Para Santos (1987), a distribuição dos serviços públicos, comércios e das amenidades, possuem uma correlação entre localização, nível social e renda. Essa perspectiva explica a centralidade que Montes exerce na região Norte de Minas em setores diversos.Merece destaque, no entanto, o fato de somente $6 \%$ dos entrevistados destacarem a Segurança como um problema. Isso significa que nas pequenas cidades a percepção sobre a segurança pública os coloca distante do que cotidianamente se verifica nas grandes e médias cidades. 
O desemprego foi apontado pelos entrevistados entre os principais problemas urbanos. Sabe-se que a oferta de emprego pelo poder público e também por entidades privadas, é importante para a geração de renda e, com isso, acesso da população a bens, serviços como saúde e educação, além de equipamentos urbanos.

Os problemas apontados pela população entrevistada não são novos e retratam a realidade de grande parte das cidades do Brasil, salvo as suas especificidades. Tal problemática demanda solução. A gestão pública, mencionada pelos entrevistados (gráficos 2 e 3), deve visar acesso, melhoria e financiamento de serviços urbanos. Trata-se de um desafio que precisa ser enfrentado para a melhoria da qualidade de vida da população.

Os entrevistados foram indagados sobre quais as soluções para os problemas do município por eles apontados (Gráfico 2). Merece destaque a percepção sobre a qualidade da gestão pública e sobre a falta de investimentos. Isso significa que para 58\% dos entrevistados os problemas do município se resolveriam pela melhoria da gestão pública e pelo aumento dos investimentos.

\section{Gráfico 2 - SOLUÇÕES APONTADAS}

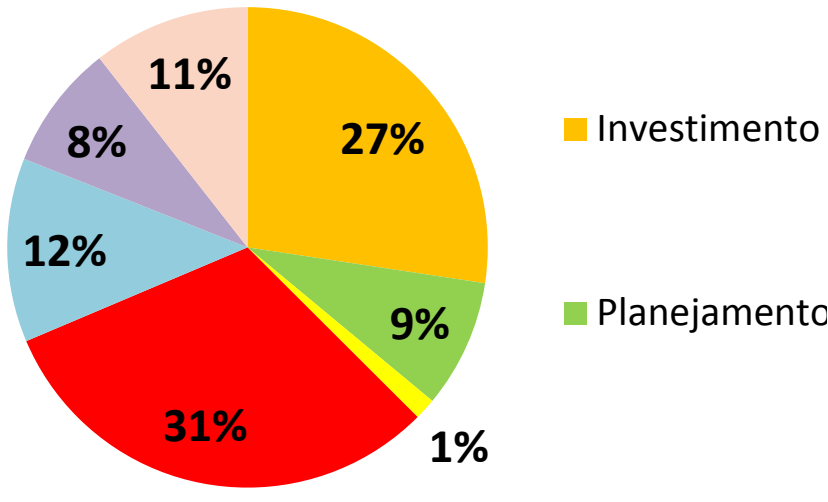

Fonte: Pesquisa Direta, 2018.

O Planejamento, a Fiscalização e a Cobrança e Participação Social, elementos que envolvem o controle dos cidadãos sobre a gestão dos recursos públicos também são apontados como soluções, mas somente para $22 \%$ dos entrevistados. Este percentual que revela uma baixa preocupação local com 0 envolvimento da população diante dos processos de planejamento, gestão, isto é, participação social. Esta será analisada mais profundamente nesse artigo a partir do gráfico 3.

Os entrevistados foram questionados ainda sobre quais são os Principais Responsáveis para os Problemas e também quanto o encaminhamento das soluções apontadas. (Gráfico 3). Destaca-se que para 90\% dos entrevistados é a Gestão Pública a responsável pelos Problemas e pelas Soluções, isto é defendem um planejamento urbano a partir da intervenção estatal para resolver os problemas urbanos apontados, entre eles, oferecer os diversos serviços urbanos. Sabe-se que a intervenção pública é importante, mas deve considerar a realidade e as transformações específicas de cada cidade.

Gráfico 3 - PRINCIPAIS RESPONSÁVEIS

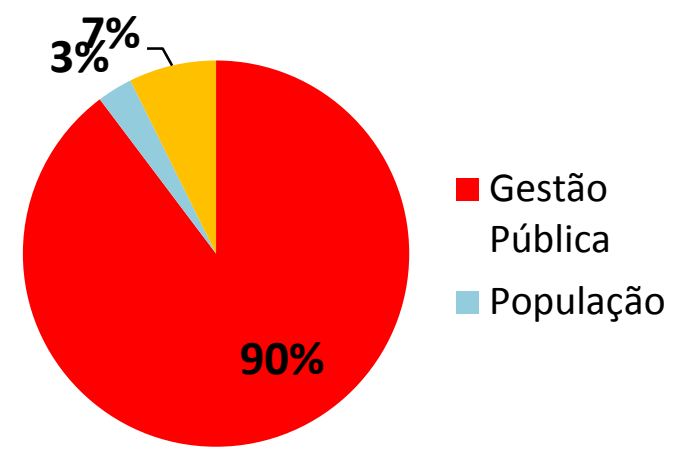

Fonte: Pesquisa Direta, 2018.

Somente $10 \%$ dos entrevistados incluem a população como parte responsável. Isso indica que há uma visão populacional que transfere para o ente público as soluções dos problemas urbanos. Assim, permite-se compreender porque apenas 22\% dos entrevistados apontaram o Planejamento, a Participação Social e a Fiscalização como parte das soluções (Gráfico 2).

$\mathrm{Na}$ tabela 1 pode-se verificar que dentre os onze municípios pesquisados somente cinco (Janaúba, Januária, Pirapora, Bocaiuva e Francisco Dumont) possuíam o Plano Diretor em 2015, quando da pesquisa realizada pelo IBGE. Dos municípios analisados nessa pesquisa com população inferior a 
20 mil habitantes, apenas Francisco Dumont possui o Plano Diretor.

Tabela 1 - Municípios: população estimada 2018 e existência de Plano Diretor/PD.

\begin{tabular}{l|l|l|l}
\hline \multicolumn{5}{c}{$\begin{array}{l}\text { População } \\
\text { Estimada }\end{array}$} & \multicolumn{1}{l}{$\begin{array}{l}\text { PLANO } \\
\text { Municípios }\end{array}$} & \multicolumn{1}{l}{$\begin{array}{l}\text { ANO } \\
\text { [2018] }\end{array}$} & \multicolumn{1}{l}{ DIRETOR̃O } \\
\hline Glaucilândia & 3.136 & NÃO & - \\
\hline Francisco Dumont & 5.187 & SIM & \multicolumn{2}{l}{2009} \\
\hline Itacambira & 5.353 & NÃO & - \\
\hline Japonvar & 8.556 & NÃO & - \\
\hline Mirabela & 13.557 & NÃO & - \\
\hline Capitão Enéas & 15.153 & NÃO & - \\
\hline Grão Mogol & 15.779 & NÃO & - \\
\hline Bocaiúva & 49.942 & SIM & 2006 \\
\hline Pirapora & 56.208 & SIM & 1997 \\
\hline Januária & 67.628 & SIM & 2008 \\
\hline Janaúba & 71.265 & SIM & 2015 \\
\hline
\end{tabular}

Fonte: IBGE, Perfil dos Municípios Brasileiros, 2015. Org.: FRANÇA, I.S.de.; 2018.

No Brasil, a partir do Estatuto da Cidade - Lei 10257 (2001), somente os municípios com população superior a 20 mil habitantes são obrigados a terem o Plano Diretor (PD). Na média brasileira 68\% dos municípios com população até 20 mil habitantes não possuem Plano Diretor (IBGE, 2015). Isso faz com que o planejamento dos municípios se torne mais distante da população, pois o PD é um instrumento que pode ser indutor da participação social e do envolvimento local com a fiscalização da gestão dos recursos públicos para melhorar a qualidade de vida urbana. Para sua eficácia, é necessário uma mobilização que vise a mudança da realidade de vida urbana. No gráfico 4 observa-se que somente $5 \%$ da população entrevistada nos municípios que possuem Plano Diretor o conhece. Isso revela um processo de planejamento e gestão urbana local distante da população.
GRÁFICO 4 - SOBRE O CONHECIMENTO DO PLANO DIRETOR

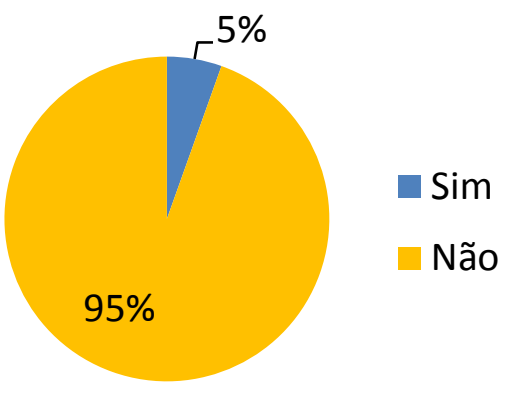

Fonte: Pesquisa Direta, 2018.

Dentre os $5 \%$ (Gráfico 4) que responderam que conhecem o Plano Diretor, diagnosticou-se que somente $16 \%$ participaram do processo de elaboração do Plano Diretor do seu município (Gráfico 5).

\section{GRÁFICO 5 - PARTICIPAÇÃO NA ELABORAÇÃO DO PLANO DIRETOR}

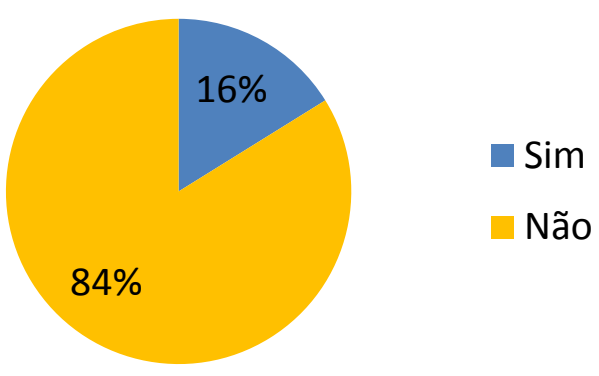

Fonte: Pesquisa Direta, 2018.

Estes dados revelam a insuficiência, a limitação e o caráter tecnocrata instalado nos processos de planejamento e gestão das cidades, para além dos problemas urbanos. Insere-se aí a necessidade da participação da população nesses processos.

Diante do exposto, os dados demonstrados nos gráficos 1 a 5 permitem indicar que há uma avaliação da população, das pequenas cidades do Norte de Minas aqui analisadas, de que os principais problemas elencados, notadamente, em relação à saúde pública e infraestrutura, tem na gestão pública o principal responsável pelas soluções. Evidenciou-se ainda, que a população não se vê como parte importante das soluções, em decorrência disso 
verificou-se a baixa participação social nos processos de elaboração do plano diretor municipal.

Sobre esse assunto, na visão de Souza (2001), planejar a cidade e sua dinâmica, mesmo em menor escala, revela-se uma prática difícil, pois decorre de questionamentos sobre uma realidade urbana que está em constante processo de transformação. Nesse contexto, é preciso que a tarefa de planejar seja precedida de um "esforço de imaginação do futuro", ou seja, pensar o planejamento, considerando os aspectos da realidade atual, como um instrumento que antecede a elaboração e aplicação de políticas públicas futuras e viáveis.

A população é consumidora e usuário do espaço urbano. Com a participação social, os problemas urbanos podem ser pensados e debatidos com vistas a busca de solução numa visão próxima da totalidade socioespacial urbana. Do contrário, perpetuarão as ações tecnocratas dos gestores com práticas de planejamento de "cima para baixo" sem alcançar a cidade real e, com isso, a totalidade da população, notadamente, os mais pobres. As elites econômicas e políticas sentem-se ameaçadas com a participação popular pelo receio de mudanças nas bases políticas historicamente estruturadas a seu favor.

A participação social é útil no planejamento urbano, desde a leitura da realidade local com participação em reuniões e audiências públicas, até as proposições e formulações urbanas na luta por um processo de participação popular representativa e deliberativa. Para a sensibilização e capacitação da popular, aponta-se a parceria poder público e Universidade, podendo levar a uma participação plena dos cidadãos em busca de uma democracia participativa emancipatória.

\section{Considerações Finais}

A partir da análise teórica e empírica aqui efetuada, pode-se refletir e demonstrar alguns aspectos da realidade socioespacial e do planejamento e da gestão urbana em pequenas cidades do no Norte de Minas. As pequenas cidades do Norte de Minas, a exemplo de outras realidades no
Brasil, apresenta um quadro urbano com precarização de serviços públicos, decorrente da ausência ou ineficiência de políticas públicas por parte do Estado. Os principais problemas urbanos diagnosticados pelos entrevistados das pequenas cidades analisadas foram: saúde, infraestrutura, desemprego. O Estado possui um papel importante como agente transformador da realidade urbana. $O$ acesso a tais serviços são fundamentais na vida da população e podem minimizar as desigualdades sociais e espaciais.

Pirapora, Janaúba, Januária e Bocaiuva possuem população aproximada entre 50 a 70 mil habitantes e cumprem a Lei Estatuto da Cidade por possuírem o Plano Diretor Municipal. Estes municípios são sedes de suas microrregiões e exercem influência nesse âmbito. Francisco Dumond que possui população aproximada de 5 mil habitantes, se diferencia das demais pequenas cidades analisadas por possuir o referido plano. Chama a atenção no conjunto dos municípios analisados esse caso, em função da não obrigatoriedade de adoção do Plano Diretor. Por outro lado, indaga-se sobre a limitação do marco regulatório nacional ao estabelecer a obrigatoriedade de adoção do PD apenas aos municípios de médio e grande porte, bem como situações de excepcionalidade.

Indaga-se então: Por que as pequenas cidades foram excluídas do planejamento urbano brasileiro? As pequenas não possuem precariedades, problemas urbanos e desigualdades? Não precisariam de ordenamento e diretrizes? O caso aqui analisado revela o contrário, isto é, a própria logica do planejamento urbano brasileiro no capitalismo contemporâneo.

Na Política Urbana brasileira, o Plano Diretor é o instrumento da política de desenvolvimento e expansão urbana e deveria ser normativa também para os processos de planejamento e a gestão urbana em pequenas cidades. Assim sendo, este plano poderia auxiliar em políticas públicas urbanas. A elaboração do PD nas pequenas cidades poderia minimizar muitos problemas urbanos, como aqueles citados pela população entrevistada relativos ao 
acesso a serviços e equipamentos urbanos, entre outros.

Em virtude do desconhecimento do PD municipal revelou-se a não participação social em sua elaboração. Tal fato é preocupante, já que a população não se coloca como parte da solução para melhorar as condições de vida nas pequenas cidades onde residem. A CFB/1998 preceitua que é dever do município assumir a gestão territorial urbana garantindo a participação social. Destaca-se a necessidade de elaboração de planos de desenvolvimento urbano que ordenem os processos de adensamento e expansão urbana com a melhoria de infraestrutura e equipamentos urbanos existentes e maior equidade na distribuição de recursos públicos entre os mais pobres e as classes abastadas.

A ação pública deve assegurar a ampla mobilização e participação de todos os interessados na discussão, na negociação e na tomada de decisões sobre a cidade. Não se desconsidera aqui os desafios, os limites e as dificuldades do planejamento urbano em pequenas cidades, em relação a autonomia financeira dos gestores num cenário de crise, precariedade de corpo técnico para aplicação e fiscalização da legislação urbana, o que não justificaria a sua inação. Assim, o planejamento pode minimizar os problemas urbanos.

Todavia, não se defende nesse estudo a perspectiva de que os problemas urbanos decorrem da falta de planejamento das cidades, e sim que esse processo pode minimizar tais problemas. Sinaliza-se aqui ações de planejamento e gestão urbana efetiva e com participação social, por meio do Plano Diretor e em consonância com as Normas do Estatuto da Cidade, como um mecanismo importante para a regulação e organização da dinâmica urbana, indispensável para o bom desenvolvimento urbano com tomada de decisões, gestão futura e minimização de problemas com vistas a melhoria de qualidade de vida de sua população.

Nesse direção, Villaça (2005) considera a importância do planejamento urbano para a organização da cidade, embora não se limite somente a isso, pois é um recurso para se alcançar um desenvolvimento econômico e social igualitário.

Com base nisso, a rapidez das mudanças tão evidentes impõe o desafio para os geógrafos apresentar reflexões sobre o que vem ocorrendo com as cidades e sobre o papel que a geografia urbana teria ou poderia ter na elaboração de uma leitura desses processos. Os geógrafos possuem nesta conjuntura uma dupla tarefa: Reconstruir a vida social pessoal e social num mundo urbano em constante transformação que requer posicionamentos ou omissões e, oferecer contribuição científica e política para compreender essas dinâmicas e processos, e talvez ter algum papel na produção do devir, a partir das múltiplas possibilidades que nos apresentam. (SPÓSITO, 2008, p.61)

Cabe assinalar que o desenvolvimento de estudos sobre as pequenas cidades brasileiras é importante e faz-se necessário, principalmente, por meio de pesquisas que desenvolvam pressupostos teóricos e metodológicos. Acredita-se que a tomada de conhecimento sobre estas realidades socioespaciais, distintas daquelas dos médios e grandes centros urbanos, pode se constituir em um ponto-chave para a ampliação das condições teóricas fundamentais ao aprofundamento do entendimento da urbanização brasileira. Tais bases incidirão de maneira direta na leitura do espaço geográfico e na tomada de ações que elevam a qualidade de vida urbana.

\section{Agradecimento}

Fundação de Amparo a Pesquisa do Estado de Minas Gerais - FAPEMIG.

\section{Referências}

1 AlVES, P. MELO, N. A. de. SOARES, B. R. Pequenas Cidades da Microrregião de Catalão (GO): reflexões sobre os municípios de Corumbaíba e Ouvidor (GO). Horizonte Científico, Uberlândia, vol. 1, nº. 7, p. 1-15, 2007.

2 AMORIM FILHO, Oswaldo BUENO, Maria Elizabeth Taitson; ABREU, João Figueiredo. Cidades de porte médio e o programa de ações sócio-educativo-culturais para as populações carentes do meio urbano em Minas Gerais. Boletim de Geografia Teorética, Rio Claro/SP, v. 2, n. 23-24, 1982. p. 33-46. 
3 ANDRADE, T. A.; LODDER, C. Sistema urbano e cidades médias no Brasil. Rio de Janeiro: IPEA/INPES, 1979.

4 BEAJEAU-GARNIER, Jacqueline. Geografia urbana. Tradução de Raquel Soeiro de Brito.Lisboa: Fundação Calouste Gulbenekian, 1980.

$5 \quad$ BRASIL. Presidência da República. Lei 10.257, de 10 de julho de 2001. 2001. Disponível em: <http://www.planalto.gov.br/CCIVIL/Leis/LEIS_20 01/L10257.htm>.

$6 \quad$ BRASIL. Presidência da República. Constituição Federal do Brasil de 1988. Capítulo 2. Da Política Urbana (Artigos 182 e 183). Disponível em: $<$ http://www.planalto.gov.br/ccivil_03/Constituica o/Constituicao.htm

7 CALDAS, MARIA FERNANDA. Política urbana, ação governamental e a utopia da reforma urbana no Brasil. Tese (Doutorado) - Universidade Federal de Minas Gerais/UFMG, Escola de Arquitetura.271p.

8 CARLOS, Ana Fani Alessandri. A cidade. $9^{\mathrm{a}}$ ed. São Paulo: Contexto, 2015.

9 CASTELLS, Manuel. A questão urbana. Rio de Janeiro: Paz e Terra, 1972.

10 CLARK, David. Introdução à geografia urbana. 2. ed. Rio de Janeiro: Bertrand, 1991.

11 CORREAA, Roberto Lobato. O Espaço Urbano. $4^{\mathrm{a}}$ ed. São Paulo: Editora Ática, 2005.

Reflexões sobre a dinâmica recente da rede urbana brasileira. In. Encontro da ANPUR, 9, 2001, Rio de Janeiro. ANAIS. 2001, 28 maio/1 jun., p.424-431.

Globalização e reestruturação da rede urbana: uma nota sobre pequenas cidades. Território/Lajet, Rio de Janeiro, n. 6, p. 43-53. jan./jun. 1999.

CYMBALISTA, Renato. A trajetória recente do planejamento territorial no Brasil: apostas e pontos a observar. Revista Paranaense de Desenvolvimento, Curitiba, n.111, p.29-45, jul./dez. 2006.

DUARTE, Fabio. Planejamento Urbano. Curitiba: Ibpex, 2007. 177 p.

16 ENDLICH, Ângela Maria. Pensando os papéis e significados das pequenas cidades do noroeste do Paraná. 2006. 505 f. Tese (doutorado) Universidade Estadual Paulista, Faculdade de Ciências e Tecnologia, 2006.

17 FRANÇA, lara Soares. Aglomeração urbana descontínua de Montes Claros/MG: novas configurações socioespaciais. 2012.393f Tese
(Doutorado em Geografia) - Instituto de Geografia, Universidade Federal de Uberlândia, Uberlândia: UFU, 2012.

FRANÇA, lara Soares. A cidade média e suas centralidades: O exemplo de Montes Claros no Norte de Minas Gerais. 2007.208f. Dissertação (Mestrado em Geografia)- Instituto de Geografia, Universidade Federal de Uberlândia, Uberlândia, 2007.

19 IBGE - Instituto Brasileiro de Geografia e Estatística. Censo Demográfico 2010. Rio de Janeiro: IBGE, 2010.

20 LEFEBVRE, Henri. A revolução urbana. Belo Horizonte: UFMG, 1999.

21 LEITE, Marcos Esdras. Geoprocessamento aplicado ao estudo do espaço urbano: o caso da cidade de Montes Claros/MG. 2006. $118 \mathrm{f}$. Dissertação (Mestrado em Geografia) Universidade Federal de Uberlândia, Uberlândia, 2006.

22 MARICATO, Ermínia. As idéias fora do lugar e o lugar fora das idéias: planejamento urbano no Brasil. In: ARANTES, O.; VAINER, C.; MARICATO, E. (Org.). A cidade do pensamento único; desmanchando consensos. Petrópolis: Vozes, 2000. p.121-192.

23 MONTE-MOR, Roberto Luis de Melo. Urbanização Extensiva e Economia dos Setores Populares. In: O Brasil, a América latina e Mundo: Espacialidades Contemporâneas (II). Org: Oliveira et al. Rio de Janeiro. Lamparina: Faperj, ANPEGE, 2008. p.130-146.

OLIVEIRA, Marcos Fábio Martins et al. Formação Social e Econômica do Norte de minas. Ed. Unimontes, 2000, 428p.

25 PEREIRA, A. M. A Urbanização no sertão nortemineiro: algumas reflexões. IN: PEREIRA, A. M.; ALMEIDA, M. I. S. de. (org.) Leituras Geográficas sobre o Norte de Minas Gerais. Montes Claros: Unimontes, 2004, p. 130, p.11-31.

26 PEREIRA, Anete Marília. Cidade Média e Região: o significado de Montes Claros no Norte de Minas Gerais. Instituto de Geografia, Universidade Federal de Uberlândia. Uberlândia/MG, 2007. Tese (Doutorado).

27 RIBEIRO, Ana Clara Torres Ribeiro. Sentidos da Urbanização: desafios do presente. In: SPOSITO, E. S. SPOSITO, M. E. B.. SOBARZO O. (Org.). Cidades médias: produção do espaço urbano e regional. $1^{\mathrm{a}}$. ed. São Paulo: Expressão Popular, 2006. (Série Geografia em Movimento). p.17-25.

28 ROLNIK, Raquel. O que é cidade? $4^{\mathrm{a}}$ edição. São Paulo: Brasiliense, 2005. 
30 SANTOS, M. A urbanização desigual: a especificidade do fenômeno urbano em países subdesenvolvidos. Petrópolis, Vozes: 1982.

31 SANTOS, Milton. Espaço e Sociedade: ensaios. Petrópolis: Vozes, 1979.

SANTOS, Milton. O Espaço do Cidadão. São Paulo: Editora Nobel, 1987.

SOARES, Beatriz R.; MELO,Nágela A. Cidades médias e pequenas: reflexões sobre os desafios no estudo dessas realidades socioespaciais. In: Cidades médias e pequenas: teorias, conceitos e estudos de caso. I Diva Maria Ferlin Lopes, Wendel Henrique (organizadores). Salvador: SEI, 2010. 250 p. il. (Série estudos e pesquisas, 87).

34 SOUZA, M. L. Mudar a cidade. Uma introdução crítica ao planejamento e à gestão urbanos. Rio de Janeiro: Bertrand Brasil. 2001.

SOUZA, Marcelo Lopes. Mudar a cidade: uma introdução crítica ao planejamento e à gestão urbanos. Rio de Janeiro: Bertrand Brasil, 2008.

36 SPOSITO. Maria Encarnação B. Urbanização da sociedade: reflexões para um debate sobre as novas formas espaciais. In: DAMINANI, Amélia Luísa; CARLOS, Ana Fani Alessandri; SEABRA, Odette Carvalho de Lima (Org.). O espaço no fim do século: a nova raridade. São Paulo: Contexto, 1999.

A questão cidade-campo: perspectivas a partir da cidade. In: SPOSITO, Maria Encarnação B; WHITACKER, Arthur Magon (Org.). Cidade e campo: relações e contradições entre urbano e rural. São Paulo: Expressão Popular, 2006. p. 111-155

.Capitalismo e Urbanização. 15a.ed. $1^{\mathrm{a}}$ reimpressão - São Paulo: Contexto, 2008.

39 SPOSITO, Eliseu Savério; SILVA, Paulo Fernando. Cidades Pequenas: Perspectivas teóricas e Transformações socioespaciais. Jundiaí, Paco Editorial: 2013.

40 VILLAÇA, Flávio. As ilusões do plano diretor. $2005 . \quad$ Disponível em https://www.revistas.usp.br/posfau/article/viewFil e/43479/47101.

41 WANDERLEY, Maria de Nazaré B. Urbanização e ruralidade: relações entre a pequena cidade e $o$ mundo rural. Estudo preliminar sobre os pequenos municípios em Pernambuco, Recife, 2001. Disponível em: $<$ http://www.fundaj.gov.br/observanordeste/obed 001f.html>. 